LIAMES, Campinas, SP, v. 20, 1-21, e020003, 2020

\title{
O fenômeno de nasalização em línguas Tupí-Guaraní
}

\author{
Camille Cardoso Miranda \\ PG - Universidade Estadual de Campinas, Brasil \\ Fundação de Amparo à pesquisa do estado de São Paulo \\ https://orcid.org/0000-0002-3920-6247 \\ Gessiane Lobato Picanço \\ Universidade Federal do Pará, Brasil \\ https://orcid.org/0000-0001-5699-1470
}

\begin{abstract}
This paper examines the patterns of nasalization in 15 languages of the Tupí-Guaraní family, Tupi stock. Following Walker's typological hierarchy of nasal harmony $(1998,2011)$, we compare the different behaviors of triggers and targets in nasal spread. The study also uses Ohala's $(1993)$ and Cohn's $(1990,1993)$ proposals to determine nasalization as a phonetic or a phonological process. Through a typological approach, we explore the behavior of consonants and vowels in relation to nasality, making it possible to classify them in terms of the roles they play, whether as triggers, targets, blockers or transparent segments. In addition, other aspects are also discussed, such as directionality of nasal spreading, which is predominantly left (regressive), and its domain. The results show that, in the Tupi-Guarani family, there is a predominance of nasal vowels as triggers, whereas targets are predominantly vowels, glides, glottals and liquids; voiceless obstruents generally behave as blockers, but there are languages in which they are transparent to the process. The domain of nasality is mainly local, when nasalization is triggered by a nasal consonant $(\mathrm{N})$, and at a long distance when triggered by a nasal vowel $(\tilde{\mathrm{V}})$. KEYWORDS: Phonology; Phenomenon of nasality; Tupi-Guarani languages; Phonological typology.
\end{abstract}

Resumo: Este artigo objetiva descrever os padrões do fenômeno de nasalização em 15 línguas da família Tupí-Guaraní, tronco Tupí. Para averiguação do processo de nasalidade em línguas Tupí-Guaraní utiliza-se como pressuposto teórico principal a abordagem tipológica de Walker (1998), para verificar e compreender, a partir de uma hierarquia tipológica de harmonia nasal, segmentos que podem ser gatilhos ou alvos do espalhamento nasal. O estudo também utiliza as considerações de Ohala $(1993)$ e Cohn $(1990,1993)$ para examinar o processo de nasalização como efeito fonético ou fonológico. A abordagem tipológica permitiu observar o comportamento de consoantes e vogais em relação à nasalidade, possibilitando sua classificação em termos de papéis que desempenham, sejam como gatilhos, alvos, bloqueadores ou transparentes. Além disso, verifica-se também a direcionalidade da nasalização que é predominantemente à esquerda (regressiva). Os resultados mostram que, na família Tupí-Guaraní, há o predomínio de vogais nasais como engatilhadoras, seguidas de consoantes nasais, ou ambas. Os alvos são predominantemente vogais, glides e líquidas; já as obstruintes surdas, em geral, comportam-se como bloqueadoras, mas há línguas em que elas são transparentes ao processo. O domínio da nasalidade nessas línguas é preeminentemente de dois tipos: Local, quando é consoante nasal $(\mathrm{N})$ e a longa distância quando é vogal nasal $(\tilde{V})$.

Palavras-chaves: Fonologia; Fenômeno de nasalidade; Línguas Tupí-Guaraní; Tipologia fonológica. 


\section{MIRANDA \& PICANCCO - O FENÔMENO DE NASALIZAÇ̃̃O...}

\section{Introdução}

Estudos tipológicos buscam comparar as semelhanças e diferenças entre as línguas do mundo, com o objetivo de mostrar tendências mais globais sobre determinados aspectos de suas gramáticas, sejam eles fonológicos, morfológicos, sintáticos. Mas o que dizer sobre as semelhanças e diferenças entre línguas geneticamente relacionadas? Em geral as semelhanças são atribuídas à herança genética, em que se uma característica é compartilhada pelas línguas irmãs, deve ter sido herdada da língua mãe; já suas diferenças geralmente são frutos de mudanças históricas. Neste artigo exploraremos a hipótese de que tendências universais e herança genética podem ter propriedades e resultados muito semelhantes. O fenômeno investigado será a nasalidade, dentro de uma mesma família linguística, a família Tupí-Guaraní (TG), pertencente ao tronco Tupí (Rodrigues 1986). Serão descritos os padrões de nasalização em 15 línguas dessa família Mbyá, Nhandewa e Tapiéte (Ramo I); Nheengatú (Ramo III), Suruí-Tocantins, Tembé, Parakanã e Tapirapé (Ramo IV); Anambé e Araweté (Ramo V); Kayabi e Apiaká (Ramo VI); Kamayurá (Ramo VII), Guajá e Emerillon (Ramo VIII). Essas línguas foram selecionadas por suas semelhanças e especificidades que nos permitirão averiguar os padrões de nasalização dentro de um mesmo ramo quanto fora dele. As línguas selecionadas abrangem todos os ramos propostos para a família, com exceção do Ramo II, por estar concentrado fora do território brasileiro.

A nasalização é de interesse tanto da fonética quanto da fonologia e já foi trabalhada em diferentes abordagens e modelos teóricos. Cohn (1993: 141) explica que, dentro da fonética, os estudos de nasalização estavam relacionados aos experimentos acústicos e perceptuais de vogais nasalizadas, enquanto que, na fonologia, os estudos incluíam regras de espalhamento ou de tipologia de inventários de segmentos nasais em línguas do mundo. As línguas indígenas brasileiras, nos anos 70, começaram a ser introduzidas nos estudos linguísticos internacionais. Desde os trabalhos de Gregores \& Suárez (1967) e Harrison \& Taylor (1971), as questões sobre nasalidade em línguas Tupí-Guaraní foram inseridas na literatura linguística. Por exemplo, Dooley (1984) observa que, em Guaraní, o fator mais importante que condiciona as variantes fonéticas dos segmentos fonológicos é a nasalização. Ferguson (1975) aponta que o fenômeno de nasalização é bastante produtivo nas línguas Guaraní e elas devem ser levadas em conta em qualquer análise envolvendo tal fenômeno.

Utilizando especialmente a proposta de Walker (1998, 2011), o trabalho visa compreender, a partir de uma hierarquia tipológica de harmonia nasal, o comportamento dos segmentos tanto como gatilhos quanto como alvos do espalhamento do traço [nasal] em uma família geneticamente relacionada, a família Tupí-Guaraní. Outros aspectos tipológicos como direcionalidade, domínio, segmentos bloqueadores e transparentes também serão examinados. Pretendemos averiguar, com isso, se as generalizações e especificidades da nasalidade nessas línguas são tão semelhantes que poderiam ser atribuídos a herança genética, ou se as línguas mantêm certa autonomia e, portanto, seguem padrões mais tipológicos.

O artigo apresenta três seções. Na primeira, são apresentadas informações sucintas da família e das línguas investigadas. Em seguida, discute-se o fenômeno de nasalidade, conforme Walker, Ohala e Cohn. E por último, com base no aporte teórico discutido, 
realizaremos a análise e discussão do fenômeno de nasalidade nas línguas selecionadas para este artigo. Do mesmo modo, o trabalho também apresenta algumas considerações gerais que foram discutidas ao longo dessa pesquisa.

\section{A família Tupí-Guaraní e informações gerais das línguas investigadas}

A família Tupí-Guaraní (TG) é uma das famílias que compõe o tronco linguístico Tupí, um dos agrupamentos linguísticos mais extensos da América do Sul, formado por 10 famílias (Rodrigues 1984/85): Arikém, Awetí, Juruna, Mawé, Mondé, Mundurukú, Puruborá, Ramaramá, Tuparí e Tupí-Guaraní, sendo essa última, a família mais ampla, com aproximadamente 40 línguas divididas em subgrupos, ou ramos, por Rodrigues (1984/85), Rodrigues \& Cabral (2002) e Mello (2000). Mello (2000) explica que as línguas pertencentes a esta família são fortemente relacionadas, com uma distribuição geográfica bastante ampla. Sua classificação baseia-se em estudos histórico-comparativos que, conforme Rodrigues (1986), é corroborada pela existência de correspondências regulares (de sons, palavras e de formas gramaticais) entre duas ou mais línguas, permitindo supor que essas propriedades foram herdadas de uma língua ancestral, ainda refletidas nas línguas atuais. Mello (2000: 14) explica que a família é bastante coesa, com línguas muito próximas, sendo relativamente fácil notar uma língua que destoe do padrão da família. Na subseção que segue, ilustraremos algumas considerações importantes da classificação interna dessa família na revisão realizada por Rodrigues \& Cabral (2002).

\subsection{A classificação interna da família}

Com novas informações sobre as línguas que compõem a família , e com o avanço em sua documentação, foi possível realizar uma revisão da classificação interna de Rodrigues (1984/85), de modo que "seja mostrada, com mais detalhes e por meio de evidências adicionais, a complexa ramificação dessa grande família linguística" (Rodrigues \& Cabral 2002: 327). Então, em 2002, uma revisão da classificação interna da família Tupí-Guaraní foi proposta, que permitiu escolher alguns critérios adicionais, fonológicos e gramaticais.

A revisão, segundo os autores, permitiu também a inclusão de novas línguas na família, como também a exclusão de outras; reajustou alguns subconjuntos e reformulou os critérios fonológicos e gramaticais. Rodrigues (1984/85) selecionou propriedades fonológicas e algumas propriedades gramaticais para distinguir subconjuntos dentro da família Tupí-Guaraní. Essas propriedades são: (1) Perda ou conservação total ou parcial de consoantes finais; (2) os reflexos do proto *t; (3) os reflexos do proto *ts; (4) os reflexos do proto *pw; (5) os reflexos do proto *pj; (6) conservação ou não de acento final; (7) marcas pessoais de terceira pessoa; (8) distinção da fala de homem e de mulher por meio de marcas pronominais de terceira pessoa. E, a partir dos compartilhamentos destas propriedades foram distinguidos oito subconjuntos da família Tupí-Guaraní exibidos no Quadro1 abaixo: 
MIRANDA \& PICANÇO - O FENÔMENO DE NASALIZAÇÃO...

Quadro 1: Classificação interna da família segundo Rodrigues \& Cabral (2002)

\begin{tabular}{|c|c|c|c|}
\hline RAMO I & RAMO II & RAMO III & RAMO IV \\
\hline Guarani Antigo & Guarayo & Tupí & Tapirapé \\
\hline Kaiowá & Sirionó & L. Geral Paulista & As. do Tocantins \\
\hline Nhandewa & Horá (Jorá) & Tupinambá & Parakanã \\
\hline G. Paraguaio & & Nheengatú & Suruí (Mujetire) \\
\hline Mbyá, Xetá & & & Avá-Canoeiro \\
\hline Tapiete & & & Tembé \\
\hline Chiriguano & & & Guajajára \\
\hline Izoceño (Chané) & & & Turiwára \\
\hline Guayakí (Axé) & & & \\
\hline Ramo v & Ramo VI & Ramo VII & Ramo VIII \\
\hline Araweté & Kayabi & \multirow[t]{5}{*}{ Kamayurá } & Wayampi (Oyampí) \\
\hline Ararandewára-Amanajé & Apiaká & & Wayampípukú \\
\hline Anambé do Cairarí & Paritintintín (Kagwahíb) & & Emérillon \\
\hline \multirow[t]{2}{*}{ Asuriní do Xingu } & $\begin{array}{c}\text { Tupí-Kawahíb (Tupí } \\
\text { do Machado, Pawaté, } \\
\text { Wiraféd, Uruewauwau, } \\
\text { Amondáva, Karipúna, } \\
\text { etc) }\end{array}$ & & $\begin{array}{c}\text { Jo'e, } \\
\text { Urubu-ka'apór, } \\
\text { Anambé de } \\
\text { Ehrenreich, Guajá, } \\
\text { Awré e Awrá }\end{array}$ \\
\hline & Juma & & Takunhapé. \\
\hline
\end{tabular}

Fonte: Adaptado de Rodrigues \& Cabral (2002: 335)

Do ponto de vista evolutivo, Rodrigues e Cabral (2002: 335) propõem os seguintes desmembramentos na família:

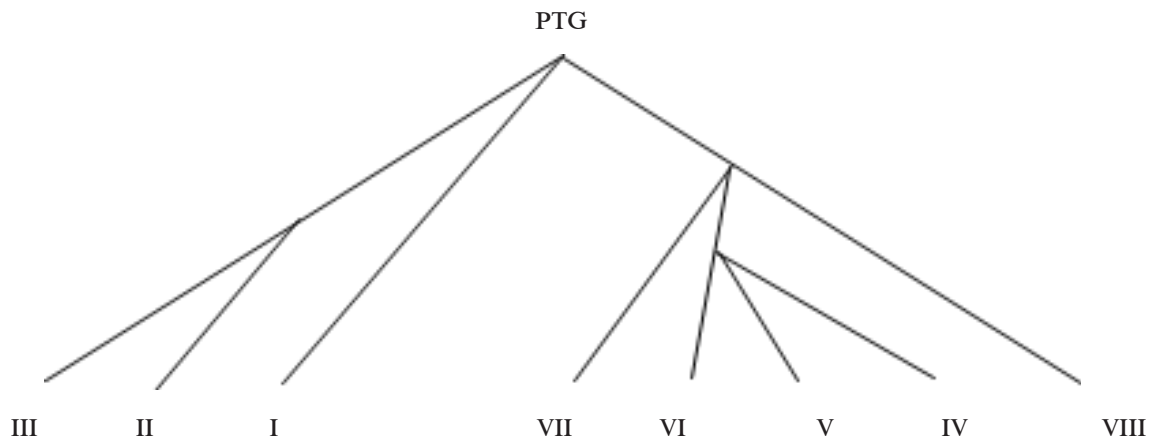

Queremos também verificar se a proximidade temporal entre os subconjuntos é refletida nos sistemas e padrões observados em harmonia nasal na família. 


\subsection{Línguas de análise}

Do total de línguas que compõem a família Tupí-Guaraní, 15 serão utilizadas para análise e discussão do fenômeno da nasalidade, abrangendo todos os ramos, com exceção do RAMO II, como já mencionado anteriormente. As línguas TG examinadas são: três línguas do RAMO I (Mbyá, Nhandewa e Tapiete); uma língua do RAMO III (Nheengatú); quatro línguas do RAMO IV (Suruí-Tocantins, Tembé, Parakanã e Tapirapé); duas línguas do RAMO V (Anambé e Araweté); duas línguas do RAMO VI (Kayabi e Apiaká); a única língua do RAMO VII, o Kamayurá, e duas língua do RAMO VIII (Guajá e Emerillon). A escolha dessas línguas foi através das observações de diferentes comportamentos relacionados à nasalização, isto é, por mais que elas sejam da mesma família elas tendem a ter algumas particularidades desse fenômeno, como vamos ver adiante. Além disso, a maioria dessas línguas também apresenta um estudo mais detalhado sobre a nasalidade.

\section{Sobre o fenômeno da nasalidade}

Um importante passo para verificar o processo de nasalidade é definir alguns aspectos que são: gatilhos, alvos e tipo de sistema (bloqueio ou transparência). Os gatilhos vão desencadear a nasalidade, podendo ser uma vogal nasal, uma consoante nasal ou um traço autossegmental. Os alvos são os elementos que, em maior ou menor grau, são suscetíveis aos efeitos da nasalidade. Há também outros segmentos que participam do processo, seja como bloqueadores, aqueles que permanecem orais e, ao mesmo tempo, interrompem o espalhamento da nasalidade; ou transparentes, aqueles que permanecem orais, mas não bloqueiam a nasalidade de segmentos adjacentes.

Enquanto processo fonológico, a nasalização é um fenômeno assimilatório, pois um segmento oral adquire o traço [nasal] a partir de um segmento nasal próximo, tornandose mais semelhante a este. Esse espalhamento pode ocorrer de três formas: da direita para esquerda, o que denominamos espalhamento regressivo; da esquerda para direita, que se refere ao espalhamento progressivo; e o espalhamento bidirecional. ${ }^{1}$ Em relação ao domínio, dizemos que o espalhamento é local, quando gatilho e alvo estão imediatamente contíguos, ou à distância, quando o traço [nasal] é transmitido de segmento a segmento, dentro de um domínio maior (por exemplo: morfema, palavra).

Parece haver consenso em diversos estudos tipológicos de que a harmonia nasal exige certa compatibilidade entre gatilhos e alvos (Cohn 1993; Walker 1998, 2000, 2011). De acordo com Walker (2011), as variações translinguísticas em harmonia nasal são limitadas por uma hierarquia de grupos fonéticos que classifica segmentos de acordo com a harmonicidade em nasalização, sendo as vogais consideradas as mais compatíveis com o traço [nasal], e as obstruintes as menos compatíveis; entre esses dois extremos estão glides, líquidas e fricativas. A hierarquia implicacional, mostrada em (1), diz que, uma vez que um segmento na escala sofre o espalhamento nasal (exemplo: líquidas), todos os segmentos à esquerda serão também atingidos (ou seja, vogais, laríngeos e glides).

${ }^{1}$ Utilizamos o termo "bidirecional" em sentido mais amplo, para referir ao espalhamento em ambas direções, mas não necessariamente de forma simultânea. 


\section{MIRANDA \& PICANÇO - O FENÔMENO DE NASALIZAÇÃO...}

(1) Escala implicacional (Walker 2011: 1839):

vogais $>$ laríngeos $>$ glides $>$ líquidas $>$ fricativas $>$ oclusivas

Partindo dessa hierarquia, verificamos que todos os segmentos altamente compatíveis com a nasalidade (mais à esquerda) serão potencialmente alvos, enquanto aqueles menos compatíveis (mais à direita) serão bloqueadores ou transparentes ao processo de nasalização. Em relação aos segmentos transparentes, eles são predominantemente limitados às classes de obstruintes surdas, uma vez que somente obstruintes têm sido observadas na superfície como oral, dentro de um contexto nasal; outros segmentos, na maioria dos casos, tornam-se nasalizados. Outra restrição encontrada pela autora é quanto aos segmentos bloqueadores que, segundo Walker (1998), vão sempre incluir as oclusivas.

Embora a proposta de Walker seja fundamental para compreender o fenômeno de nasalidade em línguas TG, sob uma perspectiva tipológica, essas línguas diferem quanto ao comportamento de segmentos laríngeos e glides, em que glides são mais suscetíveis à nasalidade do que laríngeos. Como veremos adiante, as glotais $/ \mathrm{P}, \mathrm{h} /$, frequentes nos inventários fonêmicos de línguas TG, tendem a participar do processo. No entanto, encontramos duas línguas (Anambé e Emerillon) em que parecem atuar como obstruintes. Nossa proposta é que, em termos hierárquicos, as línguas TG exibem uma inversão entre glides e laríngeos, no que os glides são mais suscetíveis à nasalização do que as glotais (laríngeos).

\section{(2) Hierarquia de harmonia nasal em línguas $T G$ :}

vogais $>$ glides $>$ laríngeos $>$ líquidas $>$ fricativas $>$ oclusivas

Outro aspecto importante a se considerar é a nasalidade enquanto efeito fonético (coarticulatório), em vez de fonológico. Para Ohala (1993: 156), a coarticulação é um termo similar à assimilação, já que ambos se referem à absorção de certos traços articulatórios de um segmento em relação a outro, devido à sua aproximação. Cohn (2007: 8) ao descrever os padrões de coarticulação também observa similaridades com os processos de assimilação, uma vez que eles recebem uma mesma explicação. Contudo, é importante compreender que os efeitos de coarticulação estão mais ligados à fonética, enquanto que os de assimilação referem-se à fonologia. Conforme Browman \& Goldstein (1992: 32), os casos de coarticulação devem-se ao fato de que vários gestos estão ocorrendo simultaneamente. No caso da nasalidade sabemos que, a principal característica de um som nasal é o abaixamento do véu palatino e, em se tratando da coarticulação, pode ocorrer uma antecipação ou prolongamento desse gesto que, por sua vez, irá se sobrepor total ou parcialmente ao segmento adjacente, o que faz com que, por exemplo, as vogais se tornem nasalizadas quando estão próximas de uma consoante nasal. Um dos critérios fundamentais que diferencia um efeito fonético de outro fonológico é obrigatoriedade no segundo, mas não no primeiro. A partir das observações realizadas, essa também é uma diferença importante entre as famílias investigadas, em que algumas línguas (principalmente as do ramo IV) exibem nasalidade coarticulatória. 


\section{4. $O$ fenômeno de nasalidade nas línguas}

\subsection{Ramo I: Mbyá, Nhandewa e Tapiete}

As línguas do RAMO I selecionadas são faladas mais ao sul do Brasil e em países vizinhos (por exemplo, Paraguai e Argentina). Em relação aos estudos, elas já contam com descrições detalhadas das respectivas fonologias e, principalmente, dos aspectos referentes à nasalidade. Desse modo, utilizamos a dissertação de Guedes (1983) para a língua Mbyá, que trata especialmente da fonologia e dos diferentes processos fonológicos encontrados nessa língua, incluindo a nasalidade; a tese de Costa (2007) para o Nhandewa, e, por fim, a tese de González (2005), para a língua Tapiete.

As três línguas examinadas desse ramo incluem vogais nasais em seus inventários, que são as principais responsáveis por iniciar o processo de harmonia, regressivamente em Mbyá e bidirecionalmente em Nhandewa e Tapiete. A seleção de alvos do processo é a mesma, que inclui vogais, glides, glotais e líquidas, como nos exemplos a seguir.

(3) Mbyá (Guedes 1983: 17-28): nasalização regressiva

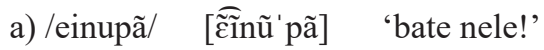
b) /awã/ [ã' $\tilde{\text { wãa }] \quad ' h o m e m ' ~}$
c) /he?ẽ/ [hẽ'?ẽ] 'é doce'

(4) Tapiete (González 2005: 46, 48, 53): nasalização bidirecional
a) /mõha/ [mõhã] 'remédio'
b) /põra/ [põ̃̃a] 'bonito'

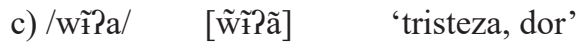
d) /hũwa/ [hũ̃̃̃a [preto'
e) $/$ arõoj $\int$ [ [ã̃̃õn $\left.\int i\right] \quad$ 'tipo de pássaro'
f) /atẽ?i/ [antẽ?ĩ] 'preguiça'
g) /pisẽwe/ [pinsẽwẽ] 'metade'

Nhandewa também exibe espalhamento bidirecional em palavras derivadas, mas somente quando o gatilho é uma vogal nasal acentuada (Costa 2007: 96), ${ }^{2}$ como no exemplo (5d), em que espalha da vogal /ã/ para os morfemas à esquerda e à direita; se o gatilho é uma consoante nasal ou pré-nasalizada, (5e), o espalhamento é só regressivo. Obstruintes surdas são transparentes em nasalização regressiva; à direita, elas sofrem alteração, tornando-se oclusivas pré-nasais vozeadas, mas também bloqueiam o processo, (5f).

${ }^{2}$ Costa (2007) fornece uma análise fonológica da nasalização da vogal como um suprassegmento (acento nasal), representado por "N" (exemplo, /petiN-tí/ 'roça de fumo'. Para manter a discussão mais clara, optamos por representá-la como vogal nasal nos exemplos. 
(5) Nhandewa (Costa 2007: 70-96)
a) วkẽ
[õ' $k \tilde{\varepsilon}]$
'porta'
b) pitã
[pr̃tã]
'vermelho'
c) kutxatĩ
[kũtyãtĩ]
'garfo'
d) nda-prã-iri

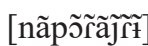
'o que não é bom, ruim'
e) r-enda
[r̃̃̃nda]
'casa, toca'
f) pet̃-ti
[pẽt̃̃ndi] 'roça de fumo'

Além da direcionalidade, outro aspecto que aproxima Nhandewa e Tapiete é quanto ao comportamento de obstruintes surdas, que são transparentes em espalhamento regressivo e bloqueadoras no espalhamento progressivo, como nos exemplos do Tapiete abaixo.

(6) Tapiete (González 2005: 46, 48, 53): bloqueio de obstruintes em nasalização progressiva
a) $/$ p̃̃sa/ [pinsa] 'dedo'
b) /tũpa/ [tumpa] 'trovão'
c) /tẽta/ [tenta] 'vila, aldeia'

Nasalização engatilhada por uma consoante nasal $(\mathrm{N})$, também ocorre nas três línguas. Em Mbyá, a nasalização, também regressiva, comporta-se igualmente àquela causada por $\tilde{v}$, afetando o mesmo grupo de segmentos (vogais, glides, glotais e líquidas) e com obstruintes transparentes ao processo.

(7) Mbyá (Guedes 1983: 19-20): nasalização condicionada por consoantes nasais

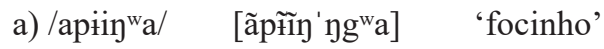
b) $/ \mathrm{momo} /$ [mõ'mbo] 'fazer saltar'
c) /nereniwa/ [nẽr̃ẽndi'wa] 'teu queixo'

Já em Nhandewa, a nasalização causada por N restringe-se à vogal imediatamente anterior, sugerindo tratar-se mais de um efeito coarticulatório que fonológico.

(8) Nhandewa: nasalização condicionada por consoantes nasais
a)/kumbanda/ [kũmã'nda] 'feijão'
b) /indambu/ [ĩnã'mbu] 'nhambu'
c) $/ \mathfrak{t} \varepsilon+$ membi/ [t

Em Tapiete, o espalhamento proeminente é o progressivo, quando as vogais nasais desencadeiam a nasalidade. No entanto, as consoantes pré-nasalizadas vozeadas também provocam o espalhamento, só que regressivo. Para González (2005: 85), "consoantes 
pré-nasalizadas vozeadas são peculiares, no que desencadeiam a nasalidade somente à esquerda", mas trata-se de um processo morfofonológico, que ocorre quando um afixo que está preso a uma raiz exibe alternância entre uma variante nasal (ex., ni-membi 'sua criança') ou uma variante oral (ndi-jiwa 'seu braço'), dependendo da presença ou ausência de um segmento nasal na raiz. Sendo assim, a língua Tapiete apresenta dois tipos de direcionalidade do espalhamento do traço [nasal]: progressivo, que é predominantemente desencadeado por $\tilde{\mathrm{v}}$, e regressivo, que é proeminente na nasalidade engatilhada por $\mathrm{N}$, em processos morfofonológicos.

O único aspecto igualmente compartilhado no Ramo I é a série de alvos, que inclui vogais, glides, glotais e líquidas, quando a nasalidade é engatilhada por ṽ. Nasalidade causada por $\mathrm{N}$ tem diferentes efeitos: fonológica em Mbyá, fonética em Nhandewa e morfofonológica em Tapiete. Os demais aspectos são diferentes: a direção do espalhamento, localidade e presença de segmentos transparentes ou bloqueadores.

\subsection{Ramo III: Nheengatú}

A língua selecionada do RAMO III foi o Nheengatú, conhecida também como Língua Geral Amazônica. Essa língua é falada principalmente nos arredores da região do rio Amazonas. Para averiguação do processo de nasalização do Nheengatú utilizamos a dissertação de Borges (1991).

A língua apresenta consoantes e vogais fonologicamente nasais como fonte do espalhamento do traço nasal. A nasalidade nessa língua também é de dois tipos: uma contextual (fonética), desencadeada por N, e uma fonológica, condicionada por ṽ. Quando a nasalidade tem como gatilho uma consoante nasal, o alvo é a vogal mais próxima; todavia, se a fonte da nasalidade é uma vogal subjacentemente nasal, a nasalidade afeta os glides, além de outras vogais. Os exemplos foram adaptados para os símbolos fonéticos do Alfabeto Fonético Internacional.

(9) Nheengatú (Borges 1991: 47-64): nasalidade regressiva, condicionada por $\tilde{v}$
a) /kiñna/
[kĩ?ĩnã]
'pimenta'
b) /kujã/
[kũ̃ãa
'mulher'
c) $/$ seẽ/
[sẽ?ẽ] [sẽẽ $]$
'doce'
d) /juntu/
[jũntu]
'sozinho'
e) /kawĩ/

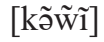
'cachaça'

(10) Nheengatú (Borges 1991: 83-84): nasalidade condicionada por $\mathrm{N}$
a) /puampe/ [puãmpe] 'unha'
b) /andira/ [ãndira] 'morcego'
c) /kambi/ [kãmbi] 'peito'
d) /anama/ [anãma] 'chuva' 
A língua apresenta como segmentos bloqueadores as obstruintes e a vibrante /r/.

(11) Nheengatú (Borges 1991: 29-64)
a) /apukuitã/
[apukui'tã]
'remo'
b) /kupĩ/
[ku' pi]
'cupim'
c) /wariã/
[wa' riã]
'batata'
d) /umaramũja/
[umarãmũ̃a]
'ele briga'

Na língua Nheengatú, a predominância é a ocorrência do espalhamento regressivo, com dois tipos de domínio: um local, por conta da consoante nasal (efeito coaticulatório), e um à distância, engatilhado por vogal nasal fonêmica, que atinge vogais e glides. A língua não possui glotais fonêmicas, segundo Borges (1991), somente [?] que pode ou não ser realizada entre vogais. Por ser a glotal epentética e opcional, consideramos que os principais alvos da nasalidade são as vogais e glides, enquanto que os demais segmentos (obstruintes e a líquida /r/) são bloqueadores.

\subsection{Ramo IV: Suruí-Tocantins, Parakanã, Tembé e Tapirapé}

As línguas TG pertencentes ao RAMO IV fazem parte do grupo Asurini-TeneteharaTapirapé, conforme a denominação de Dietrich (2015: 13). As línguas pertencentes a esse ramo têm uma particularidade no que diz respeito aos segmentos vocálicos, em que a grande maioria não apresenta vogais nasais fonêmicas. Das línguas selecionadas desse subconjunto utilizamos o trabalho de Barbosa (1993), que trata da fonologia da língua Suruí do Tocantins (Mujetire), de Gomes (1991) para analisar a nasalidade no Parakanã, de Eiró (2001) para o Tembé, e, por fim, o artigo de Leite (2003), que trata do fenômeno nasalidade das vogais em Tapirapé.

A nasalidade nas línguas Suruí-Tocantins, Parakanã e Tembé é fonética, ou seja, apresenta efeitos de coarticulação. Essas línguas não exibem vogais fonologicamente nasais, mas elas tornam-se nasalizadas por conta da influência de uma consoante nasal adjacente. Esses segmentos são os únicos engatilhadores do processo coarticulatório de nasalização nessas línguas.

(12) Suruí-Tocantins (Barbosa 1993: 23-49)
a) $/$ mitum/ [mi'tũm] 'papai!'
b) /atim/ [a'tĩm] 'eu planto'
c) /unimun/ [uni'mũn] 'saliva'

(13) Tembé (Eiró 2001: 3-4)
a) / əkəpin/ [əkə'pĩn]
'pipira'
b) /namipor/ [nãmi'por] 'brinco (enfeite)'
c) /ə-nupə/ [ə̃nu'pə] 'eu bato' 
(14) Parakanã (Gomes 1991: 32-34)
a) /paena/ [pa'z̃na]
'cesto (variedade)'
b) $/ k^{w}$ ano/ [gwã'nu $] \sim$ [gwanu $]$ 'gavião'
c) $/$ mimira/ [mi'mira $] \quad$ 'filho'

Esses exemplos mostram as consoantes nasais engatilhando a nasalização nas vogais ${ }^{3}$ à esquerda. $\mathrm{O}$ espalhamento é proeminentemente regressivo e o domínio é mais local, ou seja, abrange somente vogais adjacentes. Segundo Ohala (1981) a nasalização de uma vogal que está contígua a uma consoante nasal é um efeito de distorção fonética. Nota-se também que essa nasalidade não é sistemática, isto é, pode ou não ocorrer, diferentemente de quando a nasalidade é de natureza fonológica, obrigatória.

Já a língua Tapirapé exibe um outro padrão de nasalidade. Diferentemente das outras do Ramo IV, a língua exibe uma nasalidade desencadeada apenas por vogais fonologicamente nasais, espalhando o traço para outras vogais, glides, glotais e a líquida $/ \mathrm{r} /$; obstruintes são transparentes ao processo. Embora a língua apresente dois tipos de espalhamento, progressivo, em (15a-b), e regressivo, em (15c-f), a direcionalidade mais recorrente é o da direita para esquerda. Abaixo seguem alguns exemplos, extraídos de Leite, que demonstram o processo de harmonia nasal em Tapirapé.

(15) Tapirapé (Leite 2003: 51-57)
a) /hãwa/
['hãw̃ã]
'perna'
b) /ãpi/
['ãpĩ]
'mamãe'
c) /apẽ/
[ã'pẽ]
'está torto'
d) /ma?ẽ/
[mã'?ẽ]
'ver'
e) /marakã/ [mãrã' kã ] 'chocalho'
f) /maja/
['maja] 'cobra'

Como podemos constatar nos dados, a nasalização parece ser apenas engatilhada por vogais nasais subjacentes (o exemplo em (15f) mostra que $/ \mathrm{m} /$ não nasaliza outro segmento). Leite explica que a fonte da nasalidade não pode ser uma consoante nasal, e sim uma vogal nasal, pois "a impossibilidade da consoante nasal ser a fonte do espraiamento é a existência do contraste, entre consoante nasal seguida de vogal oral e consoante nasal seguida de vogal nasal" (Leite 2003: 55), como mostram os exemplos (15e) e (15f). A nasalidade de $\tilde{V}$ não afeta apenas o segmento vizinho, mas sim todos aqueles compatíveis (vogais, glides, glotais e líquida), e com as obstruintes sendo transparentes ao processo.

${ }^{3}$ Conforme Barbosa, a ocorrência de nasalidade em vogais que estão próximas de uma consoante nasal não é sistemática, ou seja, nem sempre ocorre. Assim, podemos verificar nos exemplos acima que tanto em Suruí quanto em Parakanã e Tembé a nasalidade da vogal contígua a uma consoante nasal não é obrigatória e pode ou não ocorrer (Barbosa 1993: 49). 


\subsection{Ramo V: Anambé e Araweté}

As línguas do RAMO v fazem parte do grupo do "Xingu-Tocantins-Gurupi" (Dietrich 2015: 14). Para averiguar o processo de nasalidade nessas línguas foram utilizados os seguintes trabalhos: a dissertação de Julião $(1993,2005)$, para a língua Anambé, e a dissertação de Alves (2008), para a língua Araweté.

As duas línguas analisadas do RAMO $\mathrm{V}$ apresentam padrões de nasalidade bastante similares. Ambas têm como engatilhadores $\mathrm{N}$ e $\tilde{\mathrm{V}}$, que é contrastiva. A nasalidade desencadeada por $\mathrm{N}$ atinge apenas vogais, enquanto que a nasalidade engatilhada por $\tilde{\mathrm{v}}$ afeta vogais e glides. Os exemplos em (16a-c) e (17a-c) ilustram a nasalização desencadeada por $\tilde{\mathrm{v}}$, e aqueles em (16d-f) e (17d-f) por N.

(16) Anambé (Julião 2005, 1993)
a) /amĩ/ [ã'mĩ $]$ 'chuva'
b) /awã / [ã' w̃̃a ] 'cabelo'

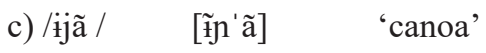
d) $/ \mathrm{kimi} / \quad$ [k̃̃'mbi] [peito'
e) $/$ nami/ [nã'mbi] 'orelha'
f) $/ \mathrm{mumu} / \quad$ [mũ'mbu $\quad$ 'furar'

(17) Araweté (Alves 2008: 36-62)
a) /je?ẽ/
[nẽ?ẽ]
'fala'
b) $/ \mathrm{t}$ ijã $/$
[tริ่'กã]
'colar'
c) /amamãj/ [ãmã'mãj]
'capim'
d) $/$ deme/ $\quad\left[\mathrm{d} \varepsilon^{\prime} \mathrm{m} \varepsilon\right] \sim\left[\mathrm{d} \tilde{\varepsilon}^{\prime} \mathrm{m} \varepsilon\right]$
'agora'
e) /imi/
['imi $] \sim[$ ĩmi $]$
'faz tempo'

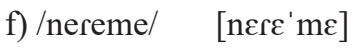
'teu lábio'

Contudo, um caso interessante de se observar na língua Anambé é o efeito de opacidade dos segmentos glotais, /, h/, mas não da vibrante /§/ que, segundo Julião (2005), assimila a nasalidade antes de interrompê-la, (18a). Para efeitos comparativos, iremos considerar que Anambé tem como alvos legítimos somente vogais e glides, enquanto que as glotais e a líquida atuam como as obstruintes, bloqueando o espalhamento. Portanto, essa língua difere de Araweté, em que as glotais são alvos e a vibrante é bloqueadora, (19a-b), assim como as demais obstruintes, como mostram os exemplos a seguir. 
(18) Anambé (Julião 2005, 1993)
a) /pirã/ [pĩ' r̃ã $]$ 'peixe'
b) /mukã/ [mu'kã $\quad$ 'espingarda
c) $/$ puhĩ/ [pu'hĩ $]$ 'remédio'
d) /upirã/ [upi' rã] 'ovo'

(19) Araweté (Alves 2008: 36-62)
a) /arã/ [a'rã $] \quad$ 'arara'
b) /iwirã/ [iwi' rã] 'pau'
c) $/$ petz̃ $/ \quad$ [pe'tĩ $] \quad$ 'fumo'
d) /ipekũ/ [ipe'kũ] 'pica-pau'
e) je?ẽ/ [nẽ?ẽ] 'fala'

$\mathrm{O}$ espalhamento de nasalidade nessas línguas é predominantemente regressivo. $\mathrm{O}$ domínio é local quando a nasalidade é condicionada por $\mathrm{N}$ e à longa distância quando a nasalidade é desencadeada por $\tilde{v}$ (caso a palavra não tenha um segmento que bloqueie o processo). Em Anambé há também a nasalização progressiva, causada por $\tilde{v}$, que ocorre em fronteiras morfológicas, afetando somente o segmento inicial do morfema.

\subsection{Ramo VI: Apiaká}

As línguas do RAMO VI são faladas entre as regiões do Amazonas, Mato Grosso e Rondônia. Para a língua Kayabi, utilizamos um trabalho de Dobson (1997) e, para a língua Apiaká, a dissertação de Padua (2007). Esse trabalho discute alguns processos preliminares da fonética e fonologia da língua e apresenta dados lexicais que colaboram com a análise.

Apesar de não haver muitos detalhes sobre a nasalização em Kayabi, Dobson (1997) reporta palavras em que vogais, glides e a glotal / / (representada na língua pelo apóstrofo) são alvos, enquanto que $/ \mathrm{r} / \mathrm{e}$ demais obstruintes parecem interromper o espalhamento regressivo do traço [nasal]. Não há indicações nos dados de que uma consoante nasal nasalize outros segmentos.

(20) Kayabi (Dobson:1997: 4-6)
a) pãjẽ 'pajé'
b) wãìĩ 'uma velha'
c) ypõ'õ 'ilha'
d) 'õ'wẽ 'mofo' 
(21) Obstruintes e /r/ bloqueando o espalhamento de nasalidade
a) itã 'concha'
b) tupã 'trovão'
c) isĩ 'ponta'
d) pirãì 'piranha'
e) irũ 'companheiro'

Já na língua Apiaká, embora o contraste entre vogais orais e nasais seja estipulado, além de consoantes nasais fonêmicas, Padua (2007) não menciona qualquer tipo de espalhamento. A maioria dos dados aponta para um sistema em que a nasalidade de segmentos nasais não causa nenhum efeito em segmentos vizinhos. Há poucos exemplos em que uma vogal aparece nasalizada quando seguida por $\mathrm{N}$ ou $\tilde{\mathrm{v}}$, sugerindo que a nasalidade pode ser resultado mais de um efeito coarticulatório do que fonológico. Além disso, diferentemente das demais línguas investigadas, a posição de uma vogal nasal na palavra é imprevisível, podendo ocorrer no início, meio ou final da palavra.

(22) Apiaká (Padua 2007: 23-36)
a) /kãwi?a/ [kãwi?a]
'mamão'
b) /nã?iwa/ [jã?iwa] [inã?iwa] 'castanheira'
c) /amãna/ [amãna] 'chuva'
d) /mutũ/ [mu'tũ $]$ 'mutum'
e) /kunã/ [kũjã] [kunã] 'mulher'
f) $/ \mathrm{si}-\mathrm{k}^{\mathrm{w}} \tilde{\mathrm{a}} /\left[\mathrm{si}^{\prime} \mathrm{k}^{\mathrm{w}} \mathrm{a}\right] \quad$ 'meu dedo'
g) /si-kuã/ [si'kũã] 'minha língua'

Como podemos verificar no exemplo (22g), a língua Apiaká tem indícios de nasalidade com domínio local e efeito regressivo, afetando, foneticamente, vogais.

\subsection{Ramo VII: Kamayurá}

A língua Kamayurá é a única língua que compõem o RAMO VII da família TG na classificação de Rodrigues \& Cabral (2002). Essa língua é falada no Alto Rio Xingu, por aproximadamente, 300 indivíduos, no Estado do Mato Grosso. A maior parte dos trabalhos realizados sobre essa língua é de Seki (2000). Dentre esses trabalhos, encontra-se a gramática da língua que é o material principal que foi utilizado para analisar o fenômeno de nasalidade em Kamayurá.

A língua apresenta consoantes nasais /m, n, y/ e há contraste entre vogais orais e nasais. Assim como ocorre na maioria das línguas investigadas, o Kamayurá apresenta dois tipos de nasalidade: uma fonética, desencadeada por $\mathrm{N}$, que engatilha seu traço [nasal] às 
vogais adjacentes, e outra fonológica, condicionada por $\tilde{\mathrm{v}}$, que afeta vogais, glides, glotais e a líquida / $/$. A língua apresenta obstruintes bloqueando a nasalidade. Os exemplos em (23) constatam os padrões de harmonia nasal encontrados na língua Kamayurá.

(23) Kamayurá (Seki 2000: 412 - 419)

Nasalidade condicionada por vogal nasal fonêmica à esquerda
a) /niwã/ [ñ̃' ũã] 'sobrinho (vocativo)'
b) /kujã/ [kũ'nã] 'mulher'
c) /ojarõ/ [õnã' r̃õ] 'está bravo'

(24) Nasalidade condicionada por consoante nasal à esquerda
a) $/$ mamae/ [mãma' $\varepsilon]$ 'espírito'
b) /manaya/ [mãyã'na] 'vespa'
c) $/$ tapen/ [ta'pẽn] ] 'tesoura pássaro'

(25) Obstruintes bloqueando o espalhamento de nasalidade
a) /tupaham/ [tu:pãhãm] ] 'corda'
b) $/$ itsĩ/ [i'tsĩ $]$ 'nariz dele'
c) $/$ mitũ/ [mi'tũ $] \quad$ 'mutum'
d) /ipisuã/ [hip̃̃̃ũ' ã] 'umbigo dele'

O espalhamento é predominantemente regressivo. Há dois domínios de nasalização: local, quando $\mathrm{N}$ desencadeia a nasalidade, ou à longa distância, quando o gatilho é $\tilde{\mathrm{v}}$, afetando toda a palavra.

\subsection{Ramo VIII: Guajá e Emerillon}

As línguas selecionadas do RAMO VIII fazem parte do grupo Amazônico Setentrional (Dietrich 2015: 14). A língua Guajá é falada por um povo que tem a mesma denominação, vivendo a noroeste do estado do Maranhão, e a língua Emerillon na Guiana Francesa, fronteira com o estado do Amapá. Para essas línguas, baseamo-nos nos trabalhos de Nascimento (2008), para a língua Guajá, e de Rose (2000, 2002) para o Emerillon, que tem uma característica importante: a ausência de fonemas nasais.

A língua Guajá exibe consoantes e vogais nasais fonêmicas; embora ambos afetem segmentos adjacentes, somente uma $\tilde{V}$ fonêmica seleciona como alvos vogais, glides, glotais e vibrante. Nasalidade desencadeada por $\mathrm{N}$ pode afetar uma vogal precedente, mas parece também tratar-se de em efeito fonético. Nessa língua, obstruintes são segmentos bloqueadores. Os exemplos em (26) exibem o padrão de nasalidade na língua Guajá. 
(26) Guajá (Nascimento 2008: 25)
a) /japijawã/
[japĩjã $\tilde{w}$ ã
'nariz'
b) /wirihã/

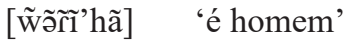
c) /ha? $/$ /
[hã?ĩ]
'caroço'
d) /wehẽ/
$[\tilde{w} \tilde{e} ' h \tilde{e}]$
'orelha dele'
e) /amĩ/
[ã' $\mathrm{m} \tilde{\imath}]$
'mamãe!'

(27) Obstruintes bloqueando o espalhamento de nasalidade (p. 25)
a) /iparawã/ [ipã̃̃̃̃̃ã] 'umbigo dele'

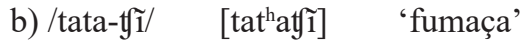

A última língua da família TG a ser analisada nesse trabalho é o Emerillon, cujo traço [nasal] é analisado como sendo autossegmental, atingindo todo o morfema (Rose, 2003). O Emerillon não exibe fonemas nasais; a nasalidade pode ser realizada no nível da palavra contendo tanto morfemas nasais quanto orais. Rose (2002: 162) explica que, embora as nasais $[\mathrm{m}, \mathrm{n}, \mathrm{n}, \mathrm{\eta}]$ sejam bastante frequentes, verifica-se a impossibilidade de uma oposição perfeita entre os sons nasais e os sons oclusivos sonoros homorgânicos [b, d, dł, g]. Desse modo, Rose propõe que as consoantes nasais são realizações fonéticas dos fonemas oclusivos sonoros, quando um morfema carrega em si o traço nasal, como nos exemplos a seguir.

(28) Nasalidade em morfemas nasais (Rose 2002: 167)

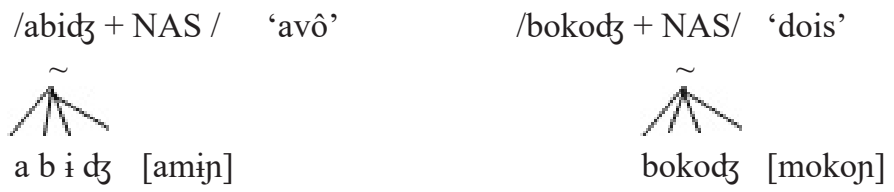

As obstruintes surdas participam do processo de harmonia nasal comportandose como elementos transparentes, classe esta que parece incluir as glotais $/ \mathrm{r}, \mathrm{h} / \mathrm{O}$ espalhamento de nasalidade é predominantemente à esquerda, ou seja, direcionalidade regressiva, tendo como alvos qualquer segmento sonoro. Rose (2002) também reporta a nasalização contextual, condicionada por consoante pré-nasalizada, mas que é só uma forma alternativa, local, atingindo apenas a vogal antecedente, portanto, fonética.

\subsection{Padrões tipológicos de nasalidade em línguas TG}

Observamos que as línguas TG compartilham alguns padrões de nasalidades e divergem em outros. Não se observa um padrão coeso dentro dos subconjuntos de línguas, de modo que essas línguas tendem a definir seus próprios padrões, mesmo dentro de um 
mesmo ramo. No entanto, há certas tendências que podemos considerar na família TG como um todo.

Primeiramente, a escala proposta por Walker (2011), estabelece a seguinte hierarquia de compatibilidade com o traço [nasal]:

(29) vogais $>$ laríngeos $>$ glides $>$ líquidas $>$ fricativas $>$ oclusivas

Nas línguas investigadas, constatam-se os seguintes tipos de alvos em harmonia nasal, resumidos no Quadro 2. ( $\mathrm{V}=$ vogal; $\mathrm{G}=$ glide; $\mathrm{GT}=$ glotal; $\mathrm{L}=$ líquida; $\mathrm{O}=$ obstruinte $)$

Quadro 2: Padrões de segmentos alvos em línguas

\begin{tabular}{|c|c|}
\hline ALVOS & LÍNGUAS \\
\hline $\mathrm{V}$ & Suruí-Toc., Parakanã, Tembé (ramo IV) \\
& Apiaká (ramo VI) \\
\hline $\mathrm{V}+\mathrm{G}$ & Nheengatú (ramo III) \\
\hline $\mathrm{V}+\mathrm{G}+\mathrm{Gt}$ & Araweté (ramo V) \\
& Kayabi (ramo VI) \\
\hline $\mathrm{V}+\mathrm{G}+\mathrm{Gt}+\mathrm{L}$ & Mbyá, Nhandewa, Tapiete (ramo I) \\
& Tapirapé (ramo IV) \\
& Kamayurá (ramo VII) \\
& Guajá (ramo VIII) \\
\hline $\mathrm{V}+\mathrm{G}+\mathrm{L}$ & Anambé (ramo V) \\
\hline $\mathrm{V}+\mathrm{G}+\mathrm{L}+\mathrm{Ov}$ & Emérillon (Ramo VIII) \\
\hline
\end{tabular}

Observa-se que há uma inversão na escala, em que, se os segmentos laríngeos são alvos, os glides também são. Aliás, as glotais podem alinhar-se com obstruintes surdas, bloqueando o processo (por exemplo, Anambé) ou sendo transparentes (Emerillon). Outra divergência da escala diz respeito ao comportamento de obstruintes (fricativas e oclusivas). Nas línguas TG, a tendência é que a diferença seja entre obstruintes vozeadas e não vozeadas, no que as primeiras são mais suscetíveis à nasalização. Desse modo, propõe-se a seguinte escala para a família TG:

(30) vogais $>$ glides $>$ laríngeos $>$ líquidas $>$ obstruintes $[+$ voz $]>$ obstruintes $[-$ voz $]$

O comportamento das obstruintes também é diferente, dependendo da língua. A maioria exibe um sistema em que obstruintes bloqueiam o espalhamento, especialmente as surdas. Somente nas línguas Mbyá e Nhandewa (ramo I), Tapirapé (ramo IV) e Emerillon (ramo VIII), elas são transparentes.

Em relação aos gatilhos, a nasalização desencadeada por ṽ é claramente de natureza fonológica, além de ser o gatilho preferido. Quando a nasalidade é causada por uma consoante nasal $(\mathrm{N})$, a tendência é que seja de natureza fonética, afetando somente vogais 
próximas, com exceção da língua Mbyá (ramo I), na qual tanto ṽ quanto $\mathrm{N}$ desencadeiam o mesmo tipo de harmonia.

Sendo assim, podemos estabelecer dois tipos de domínio: um local e outro à longa distância. O domínio local ocorre quando uma consoante nasal nasaliza a vogal oral à esquerda. Como dito anteriormente, essa nasalidade é oriunda de um efeito fonético, causado pela antecipação do abaixamento do véu palatino. Por outro lado, se a nasalidade é engatilhada por $\tilde{v}$ e a palavra não tiver nenhum segmento bloqueador, o espalhamento se dá à longa distância, ou seja, o domínio é mais abrangente, nasalizando toda a palavra; o mesmo ocorre quando a nasalidade é condicionada por uma propriedade autossegmental.

A nasalidade pode ter três diferentes tipos de direcionalidade do espalhamento: à direita (progressivo) ou à esquerda (regressivo) ou, em alguns casos, bidirecional. Walker $(1998,2000)$ mostra que cada um desses tipos de espalhamento é bem atestado em línguas do mundo. Quando se trata de um espalhamento unidirecional, a autora argumenta que a nasalização à direita entre sílabas é muito mais comum do que a nasalização à esquerda. Entretanto, nas línguas analisadas nesse trabalho e na dissertação de Miranda (2018), o padrão mais comum encontrado é o da esquerda, ou seja, o espalhamento regressivo. Este espalhamento está presente basicamente em todas as línguas, independente se o gatilho é consoante nasal ou vogal nasal subjacente. Nasalização progressiva também é observada, mas tende a ser uma propriedade morfofonológica, com exceção do Tapirapé e do Nhandewa, que ao que tudo indica, exibem espelhamento bidirecional.

\section{Considerações finais}

A proposta desse trabalho foi analisar e discutir o fenômeno de nasalização em línguas da família Tupí-Guaraní, tronco Tupí. Foram analisadas quinze línguas dessa família. O trabalho foi baseado em uma abordagem tipológica proposta por Walker (2011). Observamos que as línguas TG examinadas, embora pertençam a uma mesma família genética, não apresentam apenas semelhanças, mas também variedades nos padrões de nasalidade.

Foi visto que em relação aos segmentos alvos, as línguas foram classificadas em quatro tipos diferentes, conforme a escala implicacional de harmonia nasal. Nessas línguas, as glotais atuam, na maioria das vezes, como alvos e na classe dos glides, em virtude de elas não bloquearem a nasalidade; mesmo em línguas em que há segmentos bloqueadores; as glotais são consideradas por Walker como tendo um efeito de falsa transparência. Contudo, foi observado que em Anambé esses segmentos têm um efeito de opacidade, pois bloqueiam a nasalidade. No que diz respeito aos segmentos bloqueadores, discutiu-se que a maioria dessas línguas exibe obstruintes bloqueando a nasalidade e, raras vezes, até a vibrante tem efeito de opacidade.

A maioria das línguas exibe dois tipos de gatilhos do processo de harmonia nasal: $\mathrm{N}$ e ṽ. Vimos que há línguas que exibem a nasalidade como efeito fonético e não fonológico, geralmente quando o gatilho é N, como é o caso do Suruí-Tocantins, Parakanã, Tembé e Apiaká. Observamos também que quando o gatilho da nasalidade é N, o domínio é mais local, ou seja, restringe-se à vogal adjacente, não afetando toda a palavra, caso que não 
ocorre quando o gatilho é $\tilde{v}$, cujo domínio é mais abrangente, afetando a palavra e, por isso, pode ser considerada como uma nasalidade fonológica.

Em suma, esta pesquisa apresenta alguns pontos importantes do fenômeno de nasalidade em processos fonológicos. Espera-se que com os resultados obtidos nesse artigo possamos contribuir cada vez mais na descrição de tipologia fonológica em línguas indígenas brasileiras e nos estudos de fenômenos fonológicos em gerais.

\section{Referências}

Alves, Juliana Ferreira (2008). Fonética e fonologia da língua Araweté: Uma nova contribuição (Dissertação de Mestrado em Linguística). Brasília: Universidade de Brasília. Disponível em: https://repositorio.unb.br/bitstream/10482/3582/1/2008 JulianaFerreiraAlves.pdf

Borges, Luiz Carlos (1991). A língua geral Amazônica: Aspectos de uma fonêmica. (Dissertação de Mestrado em Linguística). Campinas: Universidade Estadual de Campinas. Disponível em: http://repositorio.unicamp.br/jspui/bitstream/REPOSIP/270456/1/Borges_LuizCarlos_M.pdf

Browman, Catherine P. \& Goldstein, Louis (1992). Articulatory phonology: An overview. Phonetica 49: 155180. Disponível em: http://www.haskins.yale.edu/sr/SR111/SR111_03.pdf Acesso: 10/10/2016

Barbosa, José Natal (1993). Contribuições à analise fonológica do Suruí no Tocantins (Dissertação de Mestrado em Linguística). Brasília: Universidade de Brasília.

Cohn, Abigail C. (1990). Phonetic and phonological rules of nasalization. UCLA Working Papers in Phonetics 76. Los Angeles, University of California, Department of Linguistics. Link: https://escholarship.org/uc/item/1xq3d5hr

Cohn, Abigail C. (1993). A survey of the phonology of the feature $[ \pm$ nasal]. Working Papers of the Cornell Phonetics Laboratory 8: 141-203.

Costa, Consuelo de Paiva Godinho (2007). Apyngwarupigwa: Nasalização em Nhandewa-Guarani (Tese de Doutorado em Linguística). Campinas: Universidade Estadual de Campinas. Disponível em: http://repositorio.unicamp.br/jspui/bitstream/REPOSIP/268994/1/Costa_ConsuelodePaivaGodinho_D.pdf

Dooley, Robert (1984). Nasalization in Guaraní. Brasília (DF): Summer Institute of Linguistics, Acervo do CEDAE, IEL - UNICAMP.

Dobson, Rose M. (1997). Gramática prática com exercícios da língua Kayabi. Cuiabá, MT.: Sociedade Internacional de Linguística. Disponível em: https://www.silbrasil.org.br/resources/archives/17087

Dietrich, Wolf (2015). O tronco Tupí e as suas famílias de línguas. Classificação e esboço tipológico. In Volker Noll; Wolf Dietrich (2015). O Português e o Tupi no Brasil, pp. 9-25. São Paulo: Contexto.

Eiró, Jessiléia Guimarães (2001). Contribuição à análise fonológica da lingua Tembé (Dissertação de Mestrado em Linguística). Belém: Universidade Federal do Pará.

Ferguson, Charles A; Hyman, Larry M. \& Ohala, John J (eds.) (1975). Nasálfest: Papers from a symposium on nasal and nasalization (Language Universals Project). Stanford, CA: Stanford University. 


\section{MIRANDA \& PICANCO - O FENÔMENO DE NASALIZAÇ̃̃O...}

Gregores, Emma. \& Suárez, Jorge A. (1967) A description of colloquial Guarani (Janua Linguarum, Series Practical 27). The Hague, Paris: Mouton \& Co.

Guedes, Marymarcia (1983). Subsídios para uma análise fonológica do Mbyá (Dissertação de Mestrado em Linguística). Campinas: Universidade Estadual de Campinas. Disponível em: http://repositorio.unicamp.br/jspui/handle/REPOSIP/270446

Gomes, Ivanise Pimentel (1991). Aspectos fonológicos do Parakanã e morfossintáticos do Awá-Guajá (Tupi) (Dissertação de Mestrado em Linguística). Pernambuco: Universidade Federal de Pernambuco.

González, Hebe Alice (2005). A grammar of Tapiete (Doctor of Philosophy). Pittsburgh. University of Pittsburgh. http://d-scholarship.pitt.edu/8444/1/HebeGonzalezDissertation.pdf

Harrison, Carl H. \& Taylor, John. M. (1971). Nasalization in Kaiwa. In David Bendor-Samuel (ed.). Tupi Studies $I$ (Linguistics and related fields 29), pp. 15-20. Norman, Oklahoma: Summer Institute Linguistics.

Julião, Maria Risolêta Silva (1993). A língua dos índios do Rio Cairari (Dissertação de Mestrado em Linguística). Belém: Universidade Federal do Pará.

Leite, Yonne Freitas (2003). A nasalidade vocálica em Tapirapé. Letras de hoje 8(34): 49-61. http://revistaseletronicas.pucrs.br/ojs/index.php/fale/article/view/13997

Mello, Antônio Augusto Souza (2000). Estudo histórico da família linguística Tupi-Guaraní - Aspectos fonológicos e lexicais (Tese de Doutorado em Linguística). Florianópolis: Universidade Federal de Santa Catarina.

Mello, Antônio Augusto Souza (2002). Evidências fonológicas e lexicais para o sub-agrupamento interno Tupí-Guaraní. In Línguas Indígenas Brasileiras: fonologia, gramática e história. Atas do I Encontro Internacional do Grupo de Trabalho sobre Linguas Indígenas da ANPOLL, t. 1, pp. 338-342. Belém: EDUFPA.

Miranda, Camille (2018). Estudo comparativo do fenômeno de nasalização em línguas da família Tupí-Guaraní (Tronco Tupí) (Dissertação de Mestrado em Letras). Belém: Universidade Federal do Pará.

Nascimento, Ana Paula (2008). Estudo fonético e fonológico da língua Guajá (Dissertação de Mestrado em Linguística). Brasília: Universidade de Brasília.

Ohala, John J. (1981). The listener as a source of sound change. In Carrie Masek; Robert A. Hendrik, and Mary Frances Miller (eds.) Papers from the parasession on language and behavior 17: 178-203. Chicago: Chicago Linguistic Society.

Ohala, John. J (1993). Coarticulation and phonology. Language and Speech 36(2/3): 155-170. https://doi.org/10.1177/002383099303600303

Padua, Alexandre Jorge (2007). Contribuições para fonologia da língua Apiaká (Tupí-Guaraní) (Dissertação de Mestrado em Linguística). Brasília: Universidade de Brasília.

Rodrigues, Aryon Dall'Igna (1984/85). Relações internas na família linguística Tupí-Guaraní. Revista de Antropologia 27/28: 33-53. Disponível em:

http://www.etnolinguistica.org/biblio:rodrigues-1985-relacoes. Acesso em: 08/08/2016. 
Rodrigues, Aryon Dall'Igna (1986). A família Tupí-Guaraní. In Línguas Brasileiras: Para o conhecimento das línguas indígenas, pp. 29-39. São Paulo: Edições Loyola.

Rodrigues, Aryon Dall'Igna; Cabral Ana Suelly Arruda Câmara (2002). Revendo a classificação interna da família Tupí-Guaraní. In Línguas indígenas Brasileiras: fonologia, gramática e história. Atas do I encontro internacional do grupo de trabalho sobre línguas indigenas da ANPOLL, t. 1, pp. 327-337. Belém: EDUFPA.

Rose, Françoise (2000). Elements de phonétique, phonologie et morphophonologie de l'émérillon (Teko) (Mémoire de D.E.A de Sciences du Langage). Lyon: Université Lumière Lyon II. HTTP://WWW.DDL.CNRS.FR/FULLTEXT/ROSE/ROSE_2000_PHONOLOGIE_EMERILLON.PDF

Rose, Françoise (2002). Le problème de la nasalité dans l'inventaire phonologique de l'émérillon. Association d'Ethno-linguistique Amérindienne, pp. 147-172. Disponível:

https://halshs.archives-ouvertes.fr/halshs-00453556/document Acesso em: 01 abr. 2017.

Seki, Lucy (2000). Gramática do Kamaiurá: Língua Tupi-Guaraní do Alto Xingu. Campinas, SP: Editora da UNICAMP.

Walker, Rachel (1998). Nasalization, neutral segments and opacity effects (Doctor of Philosophy). California: University California, Santa Cruz.

Walker, Rachel (2000). Nasalization, neutral segments and opacity effects. New York: Garland. Republished by Routledge, New York.

Walker, Rachel (2011). Nasal harmony. In Marc van Oostendorp; Colin J. Ewen; Elizabeth Hume; and Keren Rice (eds.). The Blackwell companion to phonology, vol 3, pp. 1838-1865. Wiley-Blackwell. doi: https://doi.org/10.1002/9781444335262.wbctp0078

Recebido: $11 / 4 / 2019$

Nova submissão revista: 9/3/2020

Aceito: 6/4/2020 